\title{
Abrasive Wear of Compacted Graphite Cast Iron with Added Tin
}

\author{
Yezhe Lyu ${ }^{1}$
}

Received: 2 May 2018 / Revised: 3 November 2018 / Accepted: 17 November 2018 / Published online: 27 November 2018 (c) The Author(s) 2018

\begin{abstract}
The abrasive wear behavior of traditional compacted graphite cast iron (CGI) and compacted graphite cast iron with $0.1 \%$ tin addition (CGI-Sn) is studied using a pin-on-disk tribometer. The microstructures of these two CGIs were observed by optical microscopy and scanning electron microscopy. The results show that $\mathrm{Sn}$ reduces the average size of vermicular graphite and promotes the generation of pearlite. Sn narrows the average lamellar spacing of pearlite. In the wear tests, CGI-Sn yields a decreased wear loss by $16.5 \%$ compared with CGI. Both CGI and CGI-Sn show typical abrasive worn morphology, while CGI presents a more severe wear condition in which large fragmentations can be seen. Under the current test condition, Sn is likely to improve the abrasive wear resistance of compacted graphite iron. Further studies of the specific working conditions are needed, such as testing against frictional material in braking systems, to check the validity of the findings.
\end{abstract}

Keywords Cast iron $\cdot$ Wear $\cdot$ Microstructure $\cdot \mathrm{Sn} \cdot$ Vermicular graphite $\cdot$ Brake disk

\section{Introduction}

Compacted graphite iron (CGI), also called vermicular graphite iron, is the most recent member of the cast iron family since the 1940s [1]. The vermicular-shaped (i.e., worm shaped) graphite is usually stubby with blunt edges, giving CGI a good combination of mechanical and physical properties that fall in between gray cast iron and ductile cast iron $[2,3]$. CGI offers higher strength and stiffness than gray cast iron and easier casting and higher thermal conductivity than ductile cast iron [4]. Its unique thermal fatigue resistance makes it very suitable for certain applications such as internal combustion engines and brake components $[5,6]$.

In the modern transportation era of higher speeds and capacities, CGI is increasingly used in both the railway and automobile industries to replace gray cast iron for brake disks [7-9]. During braking, the high kinetic energy of a vehicle is dissipated by frictional heat between the brake disk and brake pad [10]. Therefore, a brake disk undergoes repeated heating and cooling cycles under working conditions, making thermal fatigue a major concern for this

Yezhe Lyu

yezhe@kth.se

1 Systems and Component Design, Department of Machine Design, KTH Royal Institute of Technology, Stockholm, Sweden component. Investigations of the thermal shock behavior of cast iron with different graphite shapes have shown that CGI has higher resistance to thermal cracking than both gray cast iron and ductile cast iron $[1,5]$.

Wear resistance is another important property for brake components, and a number of investigations have demonstrated that CGI also has advantages in wear resistance over gray cast iron [7, 9]. For instance, this property was demonstrated in studies of surface oxidation and subsurface features of CGI subjected to wear $[11,12]$. Some efforts were made to enhance the wear resistance of CGI by induction hardening and laser cladding [13-16]. These methods are rather hard to perform and greatly increased the cost of production. On the other hand, alloying is likely to be an easy way to improve the properties of CGI. Copper, titanium, and tin were found to be effective in increasing the strength of CGI by promoting the formation of pearlite [17-19], but the influences of these alloys to the wear resistance of CGI is not fully understood.

The aim of this work was to study the effect of tin on the abrasive wear behavior of compacted graphite iron using a pin-on-disk test rig. Microstructure and worn surfaces were measured and analyzed to characterize the likely mechanisms of wear. 


\section{Experimental Setup}

\section{Materials}

Two types of materials were tested in this study: one conventional CGI brake disk material (here called CGI), which is used on B-segment (typical overall length 3600-4200 mm) cars in Asia, and one novel CGI brake disk material with the addition of tin (CGI-Sn). For these two materials, the content of $\mathrm{C}, \mathrm{Si}, \mathrm{Mn}, \mathrm{P}$, and $\mathrm{S}$ was fixed to the same levels so as to isolate the effect the $\mathrm{Sn}$. Table 1 shows the results of the chemical composition analysis of these two CGIs. A specimen was cast into a $\varphi 30 \mathrm{~mm} \times 20 \mathrm{~mm}$ metal mold, and the chemical analysis was carried out by spectrometry (SHIMADZUC PDA-7000 optical emission spectrometer) on the chilled specimens. Specimens for microstructure observation and wear tests were cut from brake disks cast from the same heat as the chemistry specimens.

\section{Microstructure Characterization}

Specimens for metallography were prepared by a traditional method of grinding with abrasive paper followed by polishing with $0.25-\mu \mathrm{m}$ diamond paste. Both unetched and etched specimens were observed. A ZEISS HAL100 optical microscope was used to observe the size and distribution of graphite from the unetched specimens. The specimens etched with $4 \%$ nital for $20 \mathrm{~s}$ were investigated using a PHILIPS Quanta 2000 scanning electron microscopy (SEM) to see the morphology of the matrix.

\section{Wear Testing Technique}

The wear tests were performed in a pin-on-disk tribometer test setup, in which the disk specimen was mounted horizontally and rotated by a motor. The pin specimen was held by a stationary pin holder that was vertical to the rotating disk. With this test setup, a variety of sliding contact conditions with varied contact pressures and sliding speeds can be conducted. The contact geometry used in the wear tests was a cylindrical pin $15 \mathrm{~mm}$ long with a flat 5-mm-diameter testing surface on a flat rotating corundum sandpaper. The average size of the corundum particles is $140 \mu \mathrm{m}$ according to a china foundry association standard: T/CFA 010604.06 2018. The surfaces of the pins were pre-ground to obtain a uniform initial arithmetic surface roughness ( $\mathrm{Ra}$ ) of $2 \mu \mathrm{m}$. Before testing, the pins were subjected to an ultrasonic cleaning procedure in heptane and methanol for $10 \mathrm{~min}$ each.

Every test was carried out with a new pin surface and a brand-new sandpaper to maintain the same test conditions. Each test was $30 \mathrm{~min}$ long with a contact condition of $1.0 \mathrm{MPa}$ and $0.4 \mathrm{~m} / \mathrm{s}$, giving a total sliding distance of $720 \mathrm{~m}$. Each test was repeated five times for each brake disk material under the same conditions. The wear loss of each specimen was measured by weighing the test specimen before and after the testing to the nearest $0.1 \mathrm{mg}$ using a Sartorius ME614S analytical balance. After testing, morphologies of wearing were investigated using PHILIPS Quanta 2000 SEM for analyzing the likely wear mechanisms.

\section{Results}

\section{Microstructure}

The graphite morphology of CGI and CGI-Sn specimens is shown in Fig. 1, where it can be seen that the vermicular graphite shows a homogeneous distribution in both the CGI and CGI-Sn specimens. The vermicular graphite in CGI-Sn has a smaller size on average than the CGI specimen.

Figure 2 shows the matrix morphology of the CGI and CGI-Sn specimens. In Fig. 2, the blackish worm-shaped phase is the vermicular graphite. The dark gray phase surrounding the vermicular graphite is ferrite. The shiny lamellar structured phase is pearlite. It can be seen that the traditional CGI specimen (Fig. 2a) contains a large amount of ferrite closely around the vermicular graphite. In CGI-Sn specimen (Fig. 2b), ferrite is not found and the microstructure is composed only of vermicular graphite and pearlite.

\section{Wear}

Table 2 presents the wear loss of CGI and CGI-Sn specimens, where the mean value and standard deviation of five repetitions are shown. It can be seen that CGI-Sn specimens averaged $16.5 \%$ less wear loss compared to the CGI specimens. In order to analyze the likely wear mechanisms for the tested two CGIs, typical worn surfaces of CGI and
Table 1 Chemical composition of the CGIs (wt.\%)

\begin{tabular}{llllllll}
\hline Element & $\mathrm{C}$ & $\mathrm{Si}$ & $\mathrm{Mn}$ & $\mathrm{P}$ & $\mathrm{S}$ & $\mathrm{Sn}$ & $\mathrm{Fe}$ \\
\hline CGI & 3.50 & 2.32 & 0.69 & 0.029 & 0.018 & - & Balance \\
CGI-Sn & 3.52 & 2.34 & 0.66 & 0.027 & 0.019 & 0.092 & Balance \\
\hline
\end{tabular}



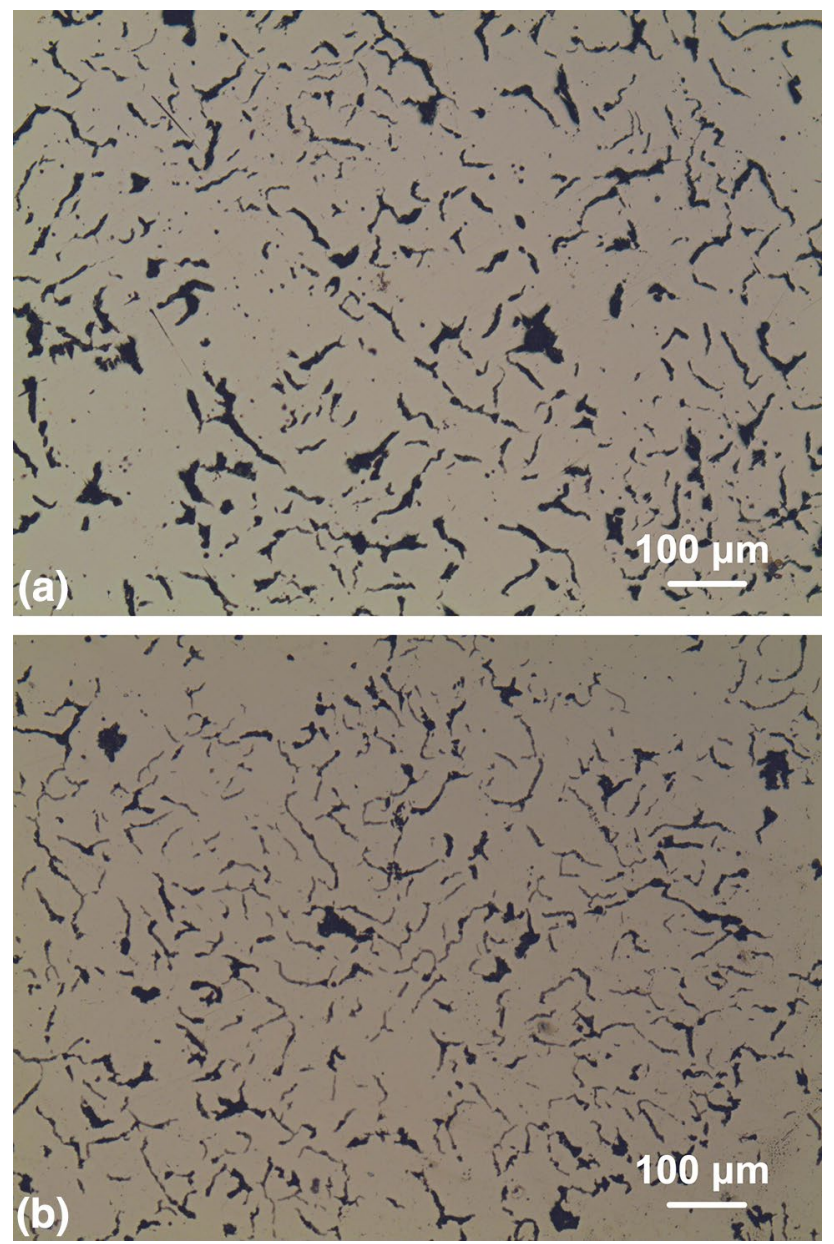

Fig. 1 Graphite morphology of (a) CGI and (b) CGI-Sn specimens

CGI-Sn at different magnifications obtained with SEM are shown in Fig. 3.

\section{Discussion}

In this study, the microstructure and abrasive wear behavior of compacted graphite cast iron (CGI) was strongly influenced by the addition of Sn.

It is suggested by Fig. 1 that $\mathrm{Sn}$ decreases the graphite size in cast iron, which agrees with the findings of Shaban et al. [20]. The possible mechanism is likely to be the low melting point of $\mathrm{Sn}\left(231.9^{\circ} \mathrm{C}\right)$. As a consequence, during solidification of molten iron, Sn will be one of the last components to solidify and will tend to stay at the front edge of the unsolidified melting, thereby hindering the growth of graphite. Figure 2 shows that the addition of $\mathrm{Sn}$ promotes the generation of pearlite in vermicular cast iron. Usually, during eutectic reaction, carbon atoms continuously move from austenite to graphite and leave a C-lack
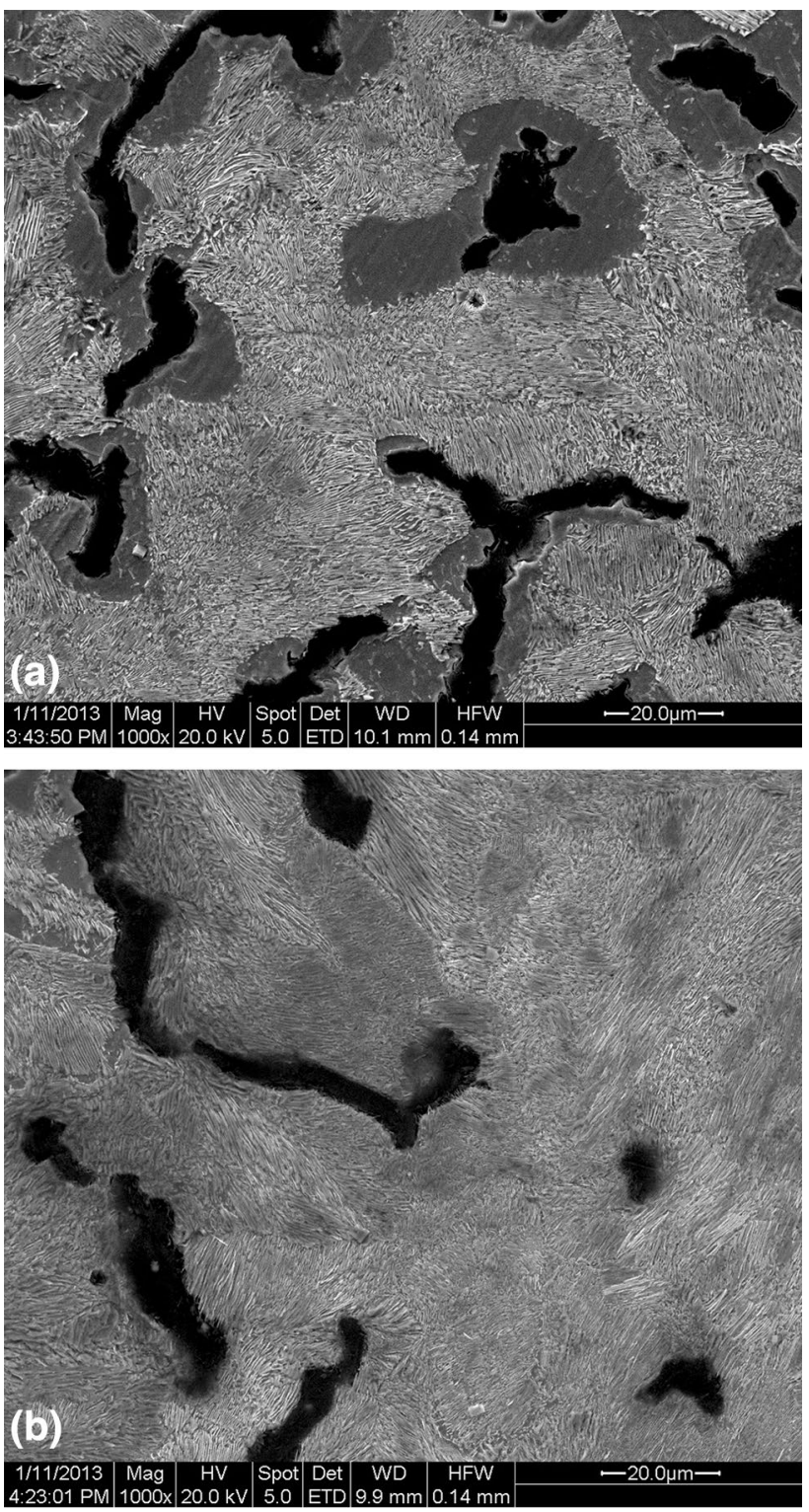

Fig. 2 Matrix morphology of (a) CGI and (b) CGI-Sn specimens [19]

Table 2 Wear losses of CGI and CGI-Sn specimens

\begin{tabular}{llr}
\hline Wear loss (mg) & Mean value & \multicolumn{1}{c}{ SD } \\
\hline CGI & 295.13 & 9.98 \\
CGI-Sn & 246.35 & 13.80 \\
\hline
\end{tabular}

area around graphite, which will finally become ferrite. Lyu et al. [19] demonstrated that Sn tends to exist at the boundary between graphite and austenite during eutectic reaction, obstructing the $\mathrm{C}$ transfer. Consequently, the areas close to vermicular graphite contained enough $\mathrm{C}$ atoms to form pearlite. 

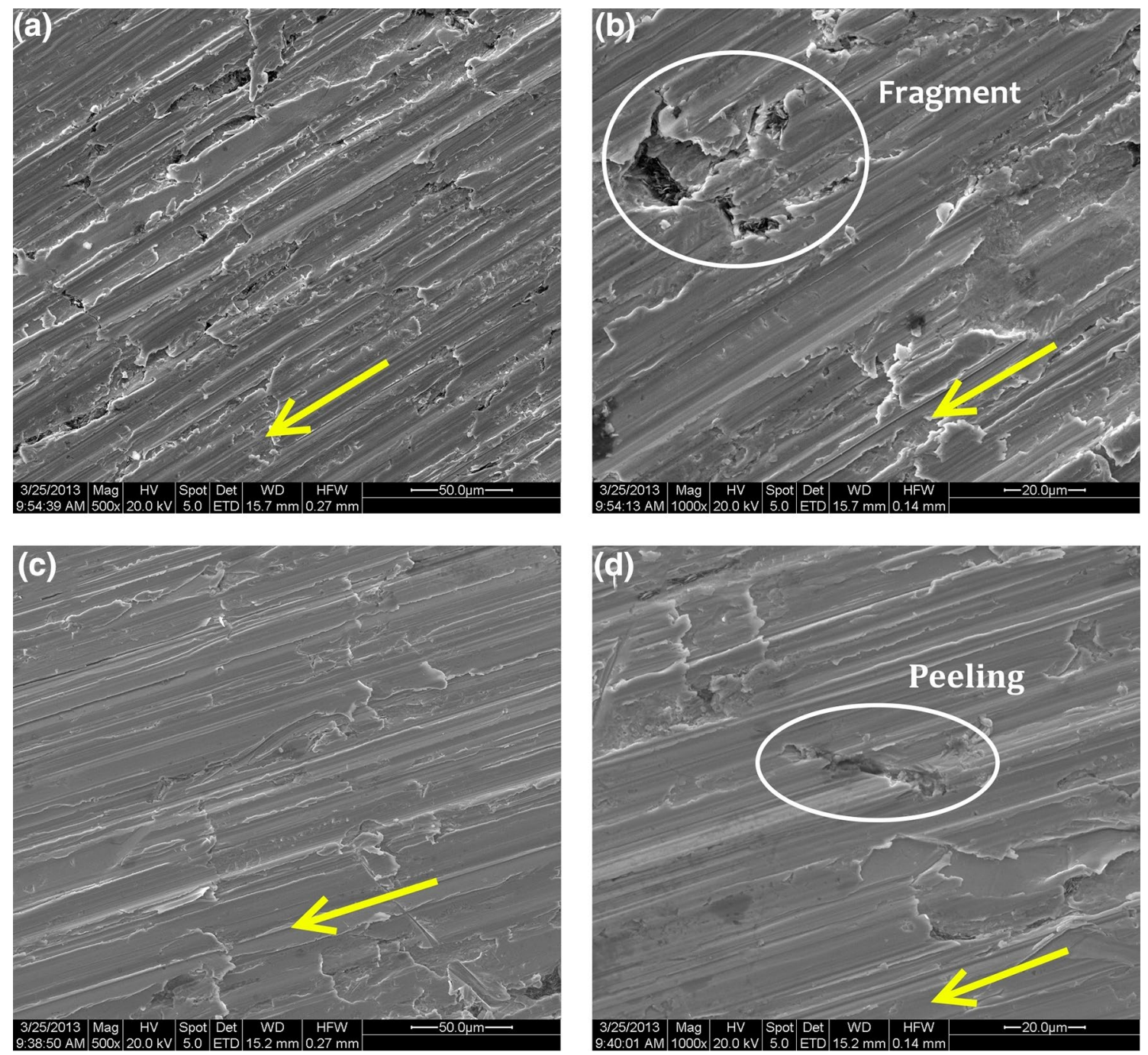

Fig. 3 Typical worn surfaces of a CGI specimen at (a) $500 \times$ and (b) $1000 \times$, and the same surfaces of a CGI-Sn specimen at (c) $500 \times$ and $($ d) $1000 \times$. The yellow arrows indicate the sliding direction

With respect to the abrasive wear test results (Table 2), it appears that the addition of Sn into CGI decreases wear loss, which could result from improvement in the microstructure (a reduction in graphite size and increase in pearlite). It is widely accepted that the properties of cast iron largely depend on the graphite morphology and matrix constitutions [1]. Graphite in cast iron yields a very low strength ( $20 \mathrm{MPa})$, much lower than a typical strength value of the matrix. Usually, the graphite is considered to be tiny inclusions in the matrix and a smaller size of graphite tends to improve the properties of cast iron. In the current study, the CGI-Sn specimen had a smaller average size of graphite compared with the CGI specimen, indicating a higher abrasive wear resistance.

In addition to the graphite morphology, matrix constitutions also contribute to the properties of cast iron. For example, the austempering process is widely used to produce bainite, which largely improves the strength and wear resistance of ductile cast iron [21]. The properties of gray cast iron and compacted graphite iron depend more on the graphite than on the matrix, making gray cast iron and compacted graphite iron to be usually used as-cast. Therefore, techniques that can increase the amount of pearlite in the cast iron matrix are of great interest in the foundry industry. Alloying additions are considered to be effective for affecting the matrix structure [6], and copper, molybdenum, and other elements have succeeded in altering the as-cast matrix from ferrite to pearlite [1], improving the mechanical properties and wear resistance. Sn added as the alloying element also promoted the generation of pearlite (Fig. 2), resulting in an increase in wear resistance (Table 2).

From the worn surfaces shown in Fig. 3, one can notice a clue to the improved wear resistance of CGI-Sn. In Fig. 3a, a severe abrasive wear morphology with a large number of 
plowing and fragmentation features can be seen. In contrast, the worn morphology of the CGI-Sn specimen in Fig. 3c indicates mild abrasive wear with cutting features on smoother surface. A large missing fragment can be seen in Fig. 3b (worn surface of CGI at high magnification). This fragment is likely to be a piece of vermicular graphite coupled with some ferrite around it (compare with the unworn matrix in Fig. 2a). Ferrite is weaker than pearlite, and it can adhere strongly to graphite. Graphite, because it is the weakest part in cast iron, has a high chance of getting sheared off during relative sliding. In the same process, a large amount of ferrite is also peeled from the surface, resulting in a high wear loss of CGI. At the same magnification, similar kinds of fragments were not found in CGI-Sn specimen (Fig. 3d). A small piece of peeling is likely to be seen on the worn surface (Fig. 3d), which looks like a piece of vermicular graphite without matrix structure around it. In Fig. 2b, one can notice that ferrite around vermicular graphite disappeared when $\mathrm{Sn}$ was added to CGI. During relative sliding, graphite was preferentially peeled off due to its low strength and weak adhesive force with the matrix structure, while pearlite remains on the surface because of its high shear strength. This appears to be the likely mechanism of the decreased wear loss of CGI-Sn specimen compared with CGI specimen (Table 2).

\section{Conclusion}

- In the testing range, Sn reduced the average size of vermicular graphite and promoted the generation of pearlite in compacted graphite iron.

- Sn-reinforced compacted graphite iron yielded a decreased wear loss by $16.5 \%$ compared to traditional compacted graphite iron.

- Traditional compacted graphite iron had wear morphology that indicated a severe wear regime, with large fragment sizes, and where scratching features can be seen.

- Sn-reinforced compacted graphite iron had a milder wear scenario with a smoother worn surface. The only peeledoff part during relative sliding was the vermicular graphite.

- Under these test conditions, Sn was likely to improve the abrasive wear resistance of compacted graphite iron. In further studies, the current findings should be validated in specific working conditions, e.g., by testing against frictional material in the application of braking systems.

Open Access This article is distributed under the terms of the Creative Commons Attribution 4.0 International License (http://creativeco mmons.org/licenses/by/4.0/), which permits unrestricted use, distribution, and reproduction in any medium, provided you give appropriate credit to the original author(s) and the source, provide a link to the Creative Commons license, and indicate if changes were made.

\section{References}

1. S. Dawson, T. Schroeder, Practical applications for compacted graphite iron. AFS Trans. 47, 1-9 (2004)

2. C. Fragassa, N. Radovic, A. Pavlovic, G. Minak, Comparison of mechanical properties in compacted and spheroidal graphite irons. Tribol. Ind. 38, 49-59 (2016)

3. T. Sjogren, P. Vomacka, I.L. Svensson, Comparison of mechanical properties in flake graphite and compacted graphite cast irons for piston rings. Int. J. Cast. Metal. Res. 17, 65-71 (2013)

4. I. Hughes, J. Powell, Compacted graphite irons-high quality engineering materials in the cast iron family. SAE Technical Paper (1984)

5. C.-H. Lim, B.-C. Goo, Development of compacted vermicular graphite cast iron for railway brake discs. Met. Mater. Int. 17, 199-205 (2011)

6. S. Kim, S.L. Cockcroft, A.M. Omran, H. Hwang, Mechanical, wear and heat exposure properties of compacted graphite cast iron at elevated temperatures. J. Alloys Compd. 487, 253-257 (2009)

7. Y. Zhang, Y. Chen, R. He, B. Shen, Investigation of tribological properties of brake shoe materials - phosphorous cast irons with different graphite morphologies. Wear 166, 179-186 (1993)

8. G. Cueva, A. Sinatora, W.L. Guesser, A.P. Tschiptschin, Wear resistance of cast irons used in brake disc rotors. Wear 255, 1256-1260 (2003)

9. K. Hirasata, K. Hayashi, Y. Inamoto, Friction and wear of several kinds of cast irons under severe sliding conditions. Wear 263, 790-800 (2007)

10. Y. Lyu, E. Bergseth, M. Tu, U. Olofsson, Effect of humidity on the tribological behaviour and airborne particle emissions of railway brake block materials. Tribol. Int. 118, 360-367 (2018)

11. Y.C. Liu, J.M. Schissler, T.G. Mathia, The influence of surface oxidation on the wear resistance of cast iron. Tribol. Int. 28, 433438 (1995)

12. V.S.R. Murthy, S. Seshan, Kishore, Subsurface features of compacted graphite cast-iron subjected to wear. Wear 97, 199-202 (1984)

13. T. Slatter, R. Lewis, A.H. Jones, The influence of induction hardening on the impact wear resistance of compacted graphite iron (CGI). Wear 270, 302-311 (2011)

14. H. Zhou, Q.-C. Guo, P.-Y. Lin, Z. Wei, X.-L. Zhang, L.-Q. Ren, Influence of $\mathrm{H} 13$ steel unit on wear behavior of vermicular cast iron. Appl. Surf. Sci. 255, 3394-3399 (2008)

15. Q.-C. Guo, H. Zhou, C.-T. Wang, W. Zhang, P.-Y. Lin, N. Sun, L. Ren, Effect of medium on friction and wear properties of compacted graphite cast iron processed by biomimetic coupling laser remelting process. Appl. Surf. Sci. 255, 6266-6273 (2009)

16. N. Sun, H. Shan, H. Zhou, D. Chen, X. Li, W. Xia, L. Ren, Friction and wear behaviors of compacted graphite iron with different biomimetic units fabricated by laser cladding. Appl. Surf. Sci. 258, 7699-7706 (2012)

17. Y.-H. Shy, C.-H. Hsu, S.-C. Lee, C.-Y. Hou, Effects of titanium addition and section size on microstructure and mechanical properties of compacted graphite cast iron. Mater. Sci. Eng. A 278, 54-60 (2000)

18. I. Andreiko, O. Ostash, V. Popovych, Influence of microstructure on the strength and cyclic crack resistance of cast irons. Mater. Sci. 38, 659-671 (2002)

19. Y. Lyu, Y. Sun, S. Liu, J. Zhao, Effect of tin on microstructure and mechanical properties of compacted graphite iron. Int. J. Cast. Metal. Res. 28, 263-268 (2015)

20. M. Shaban, A. Motallebzadeh, A. Halvaee, J. Rassizadehghani, Effect of Si content and Sn addition on solidification behavior and graphite morphology of compacted graphite iron. Int. J. Mater. Sci. Innov. 2, 87-100 (2013)

21. J. Yang, S.K. Putatunda, Effect of microstructure on abrasion wear behavior of austempered ductile cast iron (ADI) processed by a novel two-step austempering process. Mater. Sci. Eng. A 406, 217-228 (2005) 